\title{
The Design and Development of Network Learning Evaluation System Based on the Moodle platform
}

\author{
Xia Yaowen \\ Institute of Information \\ Yunnan Normal University \\ Kunming,Yunnan Province,China \\ xywen_km@sina.com
}

\begin{abstract}
This paper mainly based on Moodle network learning system evaluation theory foundation, principle of evaluation, evaluation index system, evaluation system and platform design and implementation in system, depth, and construct the content relatively complete, has the education scientific and practical evaluation system, through this platform to carry out the multiple evaluation practice, has obtained the good effect evaluation.
\end{abstract}

Keywords- Moodle, Evaluation System, The Network Learning, Scientific, Index System

\section{INTRODUCTION}

\section{A. Moodle platform overview}

Moodle all called Modular Object your Dynamic Learning Environment, Chinese translation for Modular object-oriented Dynamic Learning Environment, our country also, it is the "magic lamp" [1]. It is based on a social constructivism development concept and design of the course management system (CMS), it can be used as a traditional classroom teaching course aided and supplement, also can make a completely based on the network course. It can be in almost any kind of support PHP computer platform installation, it interface is simple, operation efficiency, good compatibility, stable performance, simple operation. In a Moodle platform most users can build thousands of door of different network course, and at the same time, the administrator can to different course classification, convenient and quick backup and restore all courses. Dr. Martin Dougiamas Moodle by Australian creative development. 21 August 2002, he issued a Moodle first version: Moodle 1.0, Moodle1.0 edition is aimed at university courses designed and developed. Along with the version of the constantly updated, more elements is injected into the Moodle, Moodle version also constantly change, to October 2010, Moodle version 2.0 release. Now, Moodle users from the university gradually spread to primary and secondary schools, companies, institutions and even the family which. According to the data provided by the Moodle.org by January 2011 so far, the world has a total of Moodle registered sites, 49854, located in 212 countries, providing course 4238093 doors, about 40117412 users [2].

\section{B. The concept of network learning evaluation}

Network learning evaluation belongs to the education evaluation subcategory, with the education evaluation of the meaning of three aspects: value judgment and evaluation of development and the reference standard. Specifically speaking, it is to point to systematically collect network learning activities in the learners' psychology and behavior of the material, analysis processing, then according to the teaching goal of the reservation to the process of learning activities and results to the process of value judgment.

Online learning the purpose of assessment is to provide timely feedback to learners, in order to promote learners' learning and improving teachers' teaching, is mainly to the learners' network learning behavior and learning results hold, judgment and evaluation, it includes results, the progress, the construction of meaning, and the power generation and other achievements and performance and specific content, and leads directly to the learning effect and efficiency of the implementation of the dynamic process of keep learners to support and quality assurance. Through the evaluation can not only understand the student's student background and the problems in the process of learning, but also through the evaluation of the achievements of students' learning, screening [3].

\section{ONLINE LEARNING SYSTEM EVALUATION INDEX SYSTEM}

\section{A. The basic concept of evaluation index system}

Learning evaluation based on students' learning goal as the basis, according to the students' learning process and learning effect, to student's learning behavior in the process of value judgment. Due to the learning goals is abstract and general principle, characteristic of, if according to the learning goals for the students to study in the judgement, it is not easy operation. Therefore, in order to smoothly carry on students' learning evaluation activity, it is necessary to abstract learning goals down into specific, measurable behavior change target, the target is called learning evaluation index[4].

\section{B. Index system evaluation met}

Used for network learning system evaluation method is very much also, based on fuzzy comprehensive evaluation method for the cases of a university to learn the network according to the following sequence for overall evaluation. The basic steps for: first of all, according to the university the course target, function of system requirements analysis, to determine evaluation index system, and the judge index system analysis, so as to determine the kinds of target is set 
up and the weight of single evaluation. Secondly, in individual evaluation, get the corresponding evaluation index system in the realization degree of different indicators, and the realization of different dimension value to a sex processing, thus get fuzzy matrix and Comprehensive evaluation again. Finally, according to the value of the total system, using the maximum membership degree principle "to get the final evaluation rating system. Such as using analytic hierarchy process to determine the weight coefficient of index, the paper adopts the fuzzy comprehensive evaluation method to study a university network in accordance with the following order integral evaluation[5][6].

\section{APPLICATION OF INFORMATION TECHNOLOGY CURRICULUM MOODLE EVALUATION}

\section{A. Application process}

Moodle is Australia teacher Martin Dougiamas development course management system. An important characteristic is Moodle construction method for design basis, its teaching module can be used free combination of dynamic modular design, the teacher use it to organize teaching like as simple building blocks. Moodle activities module includes: assignments, BBS, on-line test and feedback analysis, resources, voting, questionnaire investigation, chat room, Blog and Wiki, etc[7]. Moodle platform supports a variety of teaching and learning mode, it can make the teaching process of diversified teaching evaluation design and implementation (procedural evaluation, summative evaluation, portfolio assessment, collective evaluation and peer evaluation, teacher evaluation, and so on), it change the teacher's education idea, teaching methods and teaching ways of evaluation. This thesis mainly studies the process of Moodle sexual evaluation and summative evaluation.

\section{B. The realization of the process of evaluation}

This paper use Moodle course management system constructed a university information technology course learning, evaluation platform, as shown in figure 1 shows. Use Moodle homework, result report, test, discussion, interactive evaluation module, such as the student's information technology works and works of evaluation preservation and recorded, as part of the students' learning record, the students' learning progress for record. Moodle course management platform for comprehensive assessment of students' information technology skills, using information technology to the ability to solve practical problems and related attitudes and values of the formation of the foundation. The student with the registered user identity login system real time for teachers to I work evaluation information.

Information technology course procedural evaluation system in addition to master students in knowledge skills, emotion, and attitude and value of change and development, but also in the works and the status of the project collect valuable assessment information.

C. The realization of the summative assessment
In the information technology of class should have a balanced assessment system, as a kind of widely used evaluation method, standardized test has its continue value and meaning, the key lies in how to give full play to its own advantages, how to combine with other evaluation methods, establish a reasonable evaluation system. Use MOODLE platform, design some relevant knowledge problem, undertake to the student a test, and then quantitative students in the class, let the student and the class teacher the first time know to learning and teaching effect, as shown in figure 2 and 3 shows.

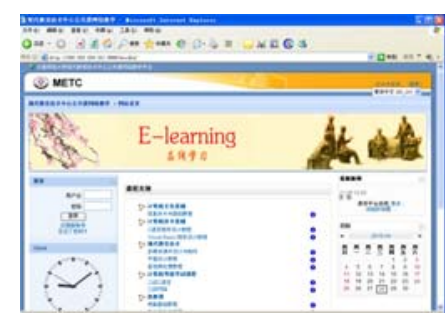

Figure 1. a university information technology course learning, evaluation platform

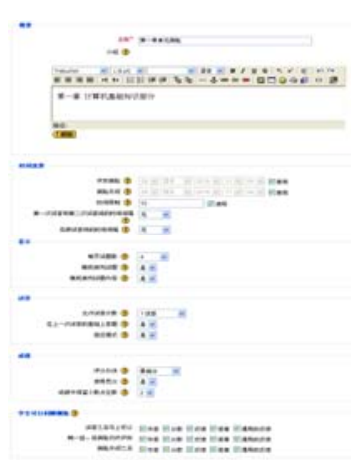

Figure 2. Summative test page

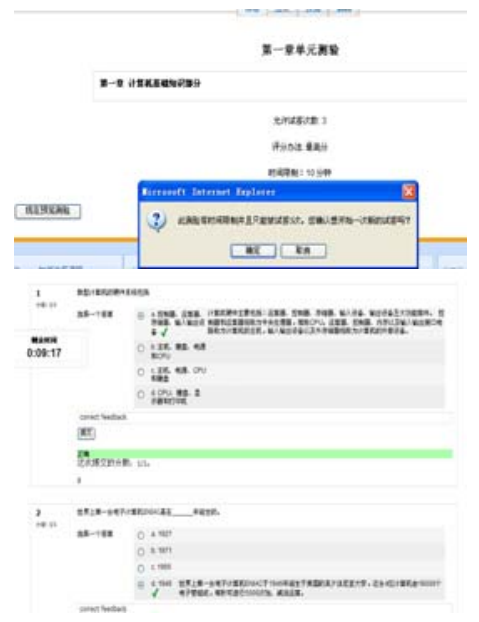

Figure 3.

Figure 4. Student test page 
Teachers using Moodle platform test and interactive evaluation module function to realize the objective questions and comprehensive task problem evaluation. The objective questions part application test module to achieve, teachers definition question bank, the topic can contain HTML and pictures, questions and answers can be random sequence (random) display, reduce cheating. Topic form is agile, single topic selection, multiple-choice questions, fills up the topic, sorting problem, matching the topic and so on questions can be arbitrary choice. Comprehensive evaluation task problem by interactive evaluation module implements. These problems will be stored in the item pool of classification, and in the course of reuse between.

\section{Diagnostic evaluation}

In addition to procedural evaluation and summative assessment in the process of teaching plays an important role, but in the process of teaching diagnostic evaluation also has an important role. For those in the process of evaluation and summative assessment for the difficulties students, must use diagnostic evaluation to determine the problem, so as to the development of students to provide the most valuable Suggestions. Then if only by teacher one-to-one counseling, will attend. And if other students to finish their work to help them, they will waste a lot of waiting time, and a lot of "helping others" students always used to instead of "waiting for help" students complete the operation, so that help make no sense. If the reference materials requires, very long time to browse through the teaching material, teaching research of many words, this just contact information technology students more difficult. Use the magic lamp platform student self-service learning platform, it can be explained in this class of operation skills and related knowledge to the words, pictures, video and so on many kinds of ways, categorization on the platform, as shown in figure 3 shows. Students through watching video, pictures, reading related words, can solve the actual operation of the problem. Make Moodle platform into an online "good teacher".

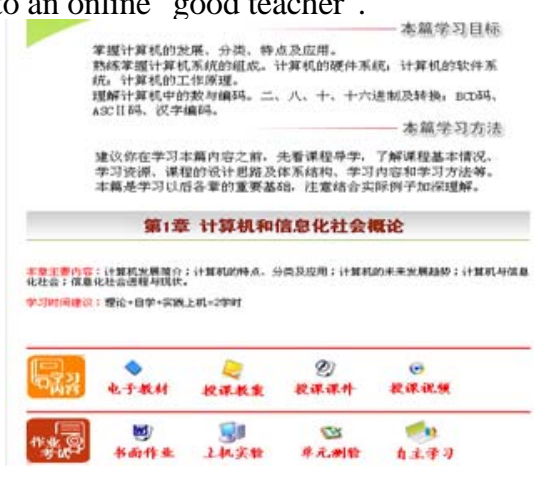

Figure 5. The cultivation of students' autonomous learning platform

According to our information technology equipment, teachers, and classes in university information technology curriculum standards, module testing by learning quality, process evaluation, put an end to the evaluation of three parts, each substation the proportion is $20 \%, 30 \%$ and $50 \%$.

After more than a year of teaching practice, using the Moodle platform constructed the information technology subject evaluation platform, make information technology curriculum evaluation is no longer to "test" and "review". Through this platform, the teacher prompt understanding students' learning situation, adjust the teaching schedule and teaching methods, education teaching effect will be elevated to a higher level.

\section{CONCLUSIONS}

This paper mainly used in Moodle online learning evaluation, fuzzy comprehensive evaluation method for evaluation of output, so that teachers can fully understand students participate in online learning, can make up for the traditional learning evaluation can only show a single final test scores shortcomings, more important is to promote students often network learning. By using this evaluation scheme thoroughly changed the students only pay attention to the exam, don't pay attention to the phenomenon of the learning process, can be more objective and timely reflect students' learning and mastery of knowledge degree, is helpful to arouse students' learning enthusiasm, cultivate students' autonomous learning ability. The diversification of student evaluation theory and the practice needs to be further improved.

\section{ACKNOWLEDGMENT}

This work is supported by the National NSF of China (No.60903131), the key project of the Education Bureau Youth Fund of Yunnan Province (No.07Z1066).

\section{REFERENCES}

[1] Li Jiahou. Moodle course design [M]. Shanghai: Shanghai education press, 2007.

[2] Moodle community [OL]. http://moodle.org

[3] Zhao Wei. Based on the electronics file network learning evaluation system design and development, open education research, 2004(4).

[4] Lv Junfeng. Based on Web network learning evaluation system [J]. Electric power informatization, 2005(1).

[5] Li Zhiping.A Web-Based Personalized Intelligent Tutoring System, In Proc. of IEEE International Conference on Information Technology in Education,2008

[6] Ding Xingfu. Remote education [M]. Beijing: Beijing normal university press, 2001.26.

[7] Zhang Weiping. Based on Moodle platform of network collaborative learning $[\mathrm{J}]$. Journal of xiangtan normal university (natural science edition), 2008(2) 